\title{
Some principles of generating seismic input for calculating structures
}

\author{
Alexander Uzdin ${ }^{1 *}$ and Sergei Prokopovich ${ }^{1}$ \\ ${ }^{1}$ Emperor Alexander I St. Petersburg State Transport University, Moskovsky pr., 9, Saint- \\ Petersburg,190031, Russia
}

\begin{abstract}
In this paper different models of seismic input are analyzed. The most essential characteristics of seismic effects are peak ground acceleration, peak ground velocity, peak ground displacement, Arias intensity, cumulative absolute velocity, seismic energy density, harmonic coefficient $\kappa$, pseudo spectral kinematic characteristics, root-mean-square peak kinematic characteristics, plastic forces work and damage spectrum. The influence of seismic impulse on characteristics of seismic input is studied. A.A. Dolgaya's and L.N. Dmitrovskaya's models with seismic impulse are compared. L.N. Dmitrovskaya's model allows to reach estimated values of energy characteristics of seismic input with the smallest deviation. When generating such processes, it is important to take into account both the properties of real actions and the limiting state of the calculated structure. The considered models of seismic inputs should be applied in the following cases: a) in case of designing mass construction projects when it is not possible to get a package of design accelerograms, b) in typical designing when the design object can be located on sites with different seismic and geological conditions, c) at early stages of designing important objects when the package of design accelerograms is not available yet but it is necessary to make technical solutions.
\end{abstract}

\section{Introduction}

In connection with the advent of new seismic protection systems and the transition to multilevel designing (Performance Based Designing or PBD) the need for dynamic calculation of structures using earthquake accelerograms arises. For calculating important structures packages of design accelerograms are usually submitted by seismologists. In most cases such packages are not available. Sometimes they can be obtained only by the end of designing, when basic technical decisions have already been made. But even when there exists a package of accelerograms its reliability often raises doubts among engineers. In this regard numerous attempts are made to generate artificial accelerograms, at least for

\footnotetext{
*Corresponding author: spr94@ outlook.com
} 
preliminary calculations and evaluations of the package of accelerograms presented by seismologists. At present, dozens of approaches to modeling seismic inputs have been proposed. In this case, the designer has no guarantee that this or that process is quite conservative and reflects the properties of real actions. This paper is devoted to the requirements for artificial accelerograms.

The simplest models of seismic input appeared at the beginning of the last century in the process of creating the modern theory of earthquake engineering. K. Suehiro and K.S. Zavriev used a section of a sinusoid to simulate seismic input (Zavriev, K.S. Dynamic Theory of Seismic Resistance, Tbilisi, 1936; Syuehiro, K. Engineering Seismology, Moscow, 1935) A widespread model of seismic input in the form of a damped sine wave was used in Russia by I.L. Korchinsky in substantiating earthquake-resistant construction standards. The said model has also been widely applied abroad [1-4]. Later it was proposed to simulate the input by functions of V.A. Gelfand (Gelfand, V.A. Refinement of SoilStructure Model with the Use of Artificial Seismograms, Neftegazovaya geologiya i geofizika, 1977), N.N. Puzyrev (Puzyrev, N.N. On Phase Distortions and Amplitude Characteristics in the Process of Installing Seismometers on Large Areas, VNII geofizika, 1957). Input modeling based on the Berlage wavelet [5-7], proposed in 1932 (Berlage, H. Seismometer, Berlin, 1932), has been widely used.

The authors of the first impact models put the problem of a qualitative analysis of seismic vibrations and did not present their models as calculation models for assessing the structure earthquake resistance. However, with the development of earthquake engineering, there arose the need to create design models. It seems important to us to single out of them mono-frequency models, models with a variable frequency, poly-frequency models, and models with a given spectrum.

Mono-frequency models are models with one prevailing frequency. We include in them not only the deterministic processes mentioned above, but also random processes that are generated by a spectral function or by a given spectrum with one prevailing frequency. These processes have a significant shortcoming: while modeling accelerations, they do not reflect real displacements at all. Seismograms obtained by integrating the initial accelerograms are not balanced, as a rule, and when they are balanced, they lead to very small displacements. They are completely unsuitable for calculating flexible and seismically isolated systems. The presence of one dangerous frequency requires creating input packages that are dangerous for different fragments of the object under consideration. An attempt to create some universal process led to models with a variable frequency. Such processes were proposed and used by V.A. Kostyrev in the Soviet Union (Vetoshkin, V.A., Kostarev, V.V., Shchukin, A.Yu. Issues of application of modern methods for seismic analysis of power equipment, Trudy ZKTI, 1984), A.T. Aubakirov (Aubakirov, A.T Special Aspects of Seismic Input Setup for Justification of Seismic Base Isolation Project, Izvestiya VNIIG,1989), as well as by H.R. Epstein in the USA (Jonson G.R., Epstein H.R. Short duration Analytic Earthquake, Proc. of the ASCE, 1976). The model of Epstein is well known $[8,9]$. Unfortunately, the available proposals have two drawbacks. Firstly, they are not balanced, i.e. at the end of the input, the base velocity is nonzero. Secondly, in fact, despite the change in frequency, the processes remain narrow-band. These issues were discussed in detail in the papers [11, 12] and covered in educational literature (Uzdin, A.M., Elizarov, S.V., Belash, T.A. Earthquake resistant design of transport buildings and structures, Moscow, 2012)

Poly-frequency models reflect seismic action properties most fully. Among these models one can note the statistical model proposed by G.V.Davydova, described in detail in the mentioned book by Uzdin, A.M., Elizarov, S.V., Belash, T.A and the model by A.A. Dolgaya (Dolgaya, A.A. The Short-time Duration Process for Earthquake Modelling, VNIINTPI, 1994), described in [10] and used in Russian Recommendations for assigning 
seismic effects for the calculation of buildings of various responsibility degrees (St. Petersburg - Petropavlovsk-Kamchatsky, KamCenter, 1996).

In the first model artificial accelerograms are constructed using two spectral density functions, one of which has a predominant accelerogram frequency, and the second has a predominant seismogram frequency. The second model is the sum of three damped sinusoids with frequencies dangerous for the construction and several undetermined parameters that should ensure the closeness of the properties of real and synthetic inputs. An analysis of this model, performed in (Smirnova, L.N., Uzdin, A.M., Prokopovich, S.V. Some Features of Modeling Design Accelerograms, Earthquake engineering. Constructions safety, 2019), showed that so far it has not been possible to ensure that all the important parameters of the model coincide with those of the real impact.

The paper discusses ways of improving input models, primarily poly-frequency ones.

\section{Methods}

\subsection{General principles for constructing seismic input models.}

General principles for constructing input models are well known [13,14].

Firstly, the design model should be more dangerous for the construction than real impacts.

Secondly, the model should be based on the expected limit state.

Thirdly, the input model should not lead to excessive costs for structure strengthening.

Fourth, despite the complexity of natural phenomena, design models should not, in their complexity, challenge the human mind.

From the above, fairly obvious principles, there are two understandable provisions that do not always find understanding among experts.

1. It is impossible to make one universal model of seismic input. For structures with a brittle destruction nature, action peak accelerations are dangerous, and for structures with a plastic destruction nature, long-term actions with high average accelerations are dangerous. The transition to multi-level PBD involves working with several limit states and, therefore, with several input models

2. Model input should not be outwardly similar to real actions. On the one hand, engineers successfully work with simple input models. What does the equivalent load used in bridge designing look like? It's just a strip of uniform load, there are no wagons or diesel locomotives in it. On the other hand, the external similarity of the two effects is extremely misleading. Figures in table 1 shows the chronograms of two processes. Their seismograms are very similar, but the corresponding speeds are already significantly different, and the accelerations are not at all similar. So are the calculated accelerograms. They can be outwardly similar to real processes, but completely unsuitable for the analysis of earthquake resistance of structures.

When generating design seismic input, the first question arises as to what characteristics of real actions can be distinguished and which of them should be taken into account in the calculation model. A description of these characteristics is given below.

\subsection{Seismic action characteristics.}

In our opinion, all characteristics of seismic effects can be divided into 3 groups: kinematic, spectral and energy ones. 
Table 1. An example of a deceptive external similarity between two processes $(y(t)$ - seismogram; $v(t)$ - velocigram; a(t)- accelerogram)

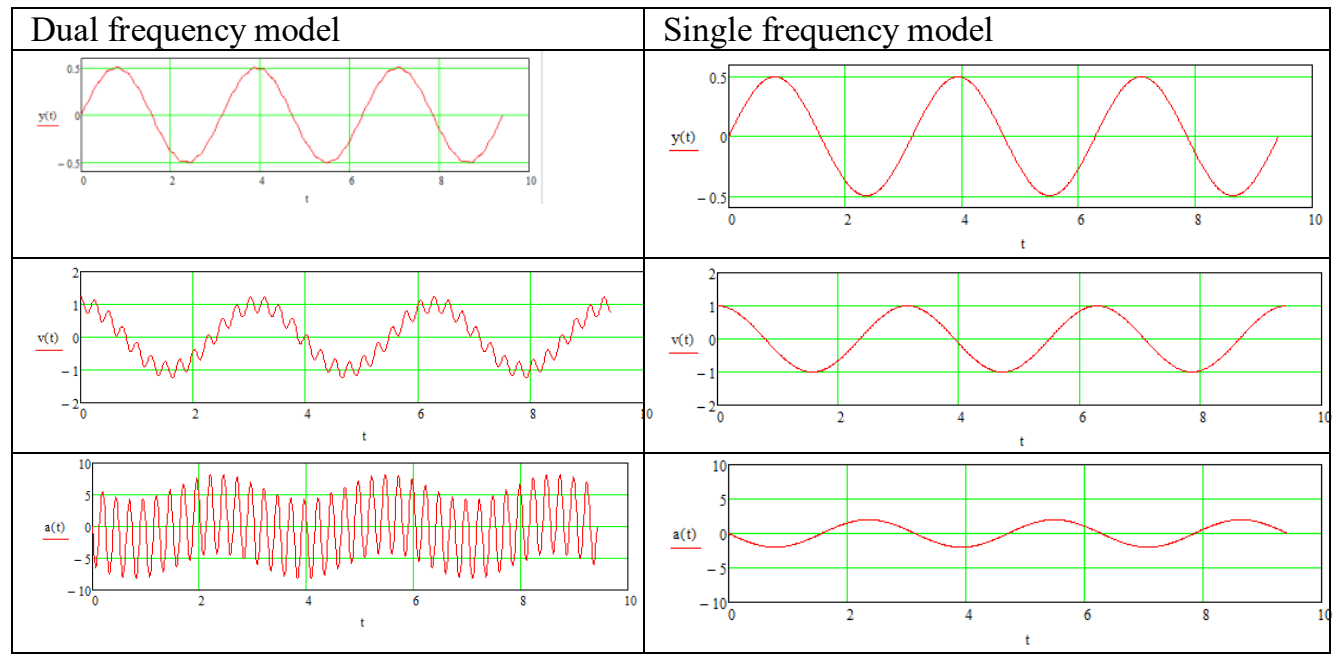

Kinematic characteristics include peak ground accelerations (PGA), peak ground velocities (PGV), peak ground displacements (PGD), residual ground displacements (RGD), and a harmonic coefficient

$$
\kappa=\frac{y_{0}^{(\max )} \cdot y_{0}^{(\max )}}{\left(y_{0}^{(\max )}\right)^{2}},
$$

where $\ddot{y}_{0}^{(\max )}$ is the peak acceleration value; $\dot{y}_{0}^{(\max )}$ is the peak velocity value; $y_{0}^{(\max )}$ is the peak displacement value.

The earthquake duration should be included in the number of kinematic characteristics, although its assessment is closely related to the energy impact characteristics.

The spectral characteristics include response spectra, primarily the acceleration spectrum and the displacement spectrum. The response spectra can be used to specify the predominant frequency of the action, but it should be borne in mind that in the acceleration spectrum and the displacement spectrum peaks are usually found at different frequencies. In addition, the pseudospectral velocity and pseudospectral acceleration can be attributed to the spectral characteristics

$$
\begin{aligned}
& \text { PSV }=\omega \cdot S_{d}, \\
& \text { PSA }=\omega^{2} S_{d}
\end{aligned}
$$

where $\omega$-dominant frequency, $S_{d}-$ maximum spectral displacement.

Energy characteristics form a large group of characteristics using which different experts tried to assess the earthquake energy transmitted to the structure [15-17]. The authors consider it necessary to highlight the following characteristics:

- Arias intensity $\mathrm{I}_{A}$ and Arias modified intensity $\mathrm{I}_{\mathrm{A}}{ }^{\prime}$ proposed by Arias in 1970 and widely used since then [18]:

$$
\begin{aligned}
& I_{A}=\frac{\pi}{2 g} \int_{0}^{\tau} \ddot{y}^{2}(t) d t \\
& I_{A}^{s}=\int_{0}^{\tau} \ddot{y}^{2}(t) d t
\end{aligned}
$$

Based on the Arias intensity, the effective duration of an earthquake is usually determined. To do this, from the total process of earthquake duration, the sections in the front and back of the process, which contribute $5 \%$ to the $\mathrm{I}_{\mathrm{A}}$ value, are cut off.

Absolute cumulative speed, CAV 


\section{$\mathrm{CAV}=\int_{0}^{\mathrm{t}}|\mathrm{y}| \mathrm{dt}$}

Potential damage index $\mathrm{I}_{\text {Araya }}$ proposed by R. Araya in 1985 and widely used in literature [19]:

$$
I_{\text {Araya }}=\frac{I_{A}^{r}}{v_{0}^{2}}
$$

where $v_{0}$ is the number of zero intersections in the accelerogram per unit time.

Seismic Energy Density SED [20]

$$
S E D=\int_{0}^{\tau} \dot{y}^{2}(t) d t
$$

Root-mean-square peak accelerations $\sigma_{\mathrm{A}}$ and peak velocities $\sigma_{\mathrm{V}}[21]$

$$
\begin{gathered}
\sigma_{A}=\sqrt{\frac{\int_{0}^{2} y_{0}^{2} d t}{\tau}}=\sqrt{\frac{I_{d, \text { mod }}}{\tau}} \\
\sigma_{V}=\sqrt{\frac{\int_{0}^{2} y_{0}^{2} d t}{\tau}} \\
I_{H}=\int_{0.1}^{2.5} \mathrm{PSV} d t,
\end{gathered}
$$

where PSV is the velocity response spectrum.

In addition to the listed characteristics, the authors consider it important to highlight the spectral energy characteristics. These are the spectra of the work of plastic deformation forces and the damage spectra.

\subsection{Proposed Impact Model}

Earlier, A.A. Dolgaya proposed an input model in which the velocigram is presented as a sum of three damped sinusoids [10]:

$$
V(t)=\sum_{i=1}^{3} A_{i} e^{-\alpha_{i} t} \sin \omega_{i} t
$$

This model has 9 parameters: three frequencies $\omega_{i}$, three damping indices $\alpha_{i}$ and three amplitudes $A_{i}$. The frequencies $\omega_{i}$ are set to be dangerous for the construction under consideration. One of the amplitudes is set so that the model process velocity at $t=0$ is equal to zero. The remaining 5 parameters should ensure that the model characteristics are consistent with the nature data. In this case the action was characterized by the PGA value, Arias intensity $\mathrm{I}_{\mathrm{A}}$, and harmonic coefficient $\kappa$. Detailed studies of the Dolgaya's model performed by the authors and described in the paper mentioned above, showed that the remaining 5 uncertain parameters of the model do not allow for sufficient accuracy of the correspondence to the model parameters and real earthquake ones.

In this regard, the authors consider it necessary to develop a more complex input model proposed in [28]. In the frame of this model the velocity is set as follows

$$
V(t)=I\left(t-t_{0}\right)+\sum_{i=1}^{3} A_{i} e^{-\alpha_{i} t}\left(1-e^{-\beta_{i} t}\right) \sin \omega_{i} t
$$

Here $\mathrm{I}(\mathrm{t})$ is the velocity impulse described in [22]in detail. It has the form of a triangle (Fig. 2), which is characterized by three parameters: the impulse duration $2 \tau$, the peak impulse value $\mathrm{V}_{0}$ and an applied time $\mathrm{t}_{0}$. According to [22], the values of $\tau$ and $\mathrm{V}_{0}$ can be expressed in terms of the depth of the source $\mathrm{H}$ and the epicentral distance $\mathrm{R}$ of the design earthquake. 


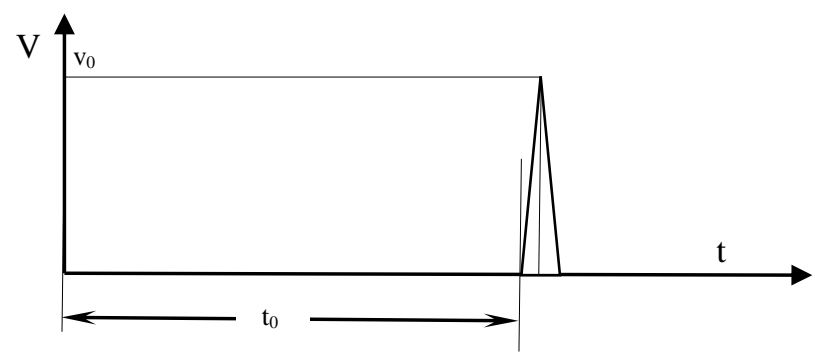

Fig.1. Impulse, added to impact

As opposed to process proposed by A.Dolgaya the process under consideration includes 12 parameters. It allows one to provide for a complete correspondence of the modal parameters to real earthquakes ones. However, to do this, it is necessary to analyze about $10^{11}$ variants of models with different parameters instead of $10^{5}$ variants in A.Dolgaya's model. To consider such a great number of variants the authors worked out a program using a video adapter which allows one to make thousands of calculations simultaneously.

\section{Results and discussion}

As an example, illustrating the possibilities of the proposed methodology, the MDE generation with the same conditions, that were used earlier, in our paper mentioned above, is considered. The prevailing input frequencies are $\omega_{1}=18.29, \omega_{2}=15.326, \omega_{3}=14.98$. Input parameters values and their weight factors are given in table 2 . The variation of weight factors is caused by different limiting states for input generation. So, to estimate the lowcycle fatigue of an structure element, the root-mean-square acceleration is important, which in its turn is determined by the Arias intensity $\mathrm{I}_{\mathrm{A}}$, and the coefficient to $\mathrm{I}_{\mathrm{A}}$ is assumed to be high $\left(\mathrm{P}_{\mathrm{IA}}=0.6\right)$, and the coefficient to peak accelerations (PGA) is accepted to be low ( $\mathrm{P}_{\mathrm{PGA}}$ $=0.1)$. The generation of a similar accelerogram for checking the throw of the bridge span off the piers is determined by the PGA value, since a one-time excess of the bearing travel for an arbitrarily small period of time will lead to a throw-off. Therefore, the option PPGA $=0.6$ and PIA $=0.1$ was considered. In all cases, for the harmonic coefficient $\mathrm{P \kappa}=0.3$.

It should be noted that the calculated value $\kappa=3.356$ was adopted for the harmonic coefficient, just as in our paper described above (Smirnova, L.N., Uzdin, A.M., Prokopovich, S.V. Some Features of Modeling Design Accelerograms, Earthquake engineering. Constructions safety, 2019). This is less than the recommended value in the US GuideLines $\kappa=5$ [23]. When setting $\kappa$, we were guided, firstly, by the fact that this quantity significantly decreases with the growth of the prevailing earthquake period and secondly, by the fact that statistics on this quantity has a large dispersion, and the lower boundary of possible values $\kappa$ should be specified with the reserve. This fact is described in Russian educational books (Uzdin, A.M., Elizarov, S.V., Belash, T.A. Earthquake resistant design of transport buildings and structures, Moscow, 2012) and scientific papers (Bogdanova, A.M., Nesterova, O.P., Nikonova, N.V., Tkachenko, A.S., Uzdin, A.M. Rakhmanova, M., Azayev, T.M., Zaynulabidova, Kh.R. Numerical earthquake characteristics, Nauka i mir, 2017).

The calculation results for various weight factors according to the two considered methods are shown in table 2 . The table shows the values of the parameters by which the input was optimized, and the values of these parameters for two generated accelerograms with the same prevailing period. As can be seen from the table, the implementation of the considered methodology substantially brings model parameters closer to actual data. 
Table 2. Comparison of two models of the calculated input generation

\begin{tabular}{|c|c|c|c|c|c|c|c|c|c|c|}
\hline \multicolumn{3}{|c|}{ Weight factors } & \multicolumn{4}{|c|}{$\begin{array}{l}\text { Parameters of generated impact by } \\
\text { Dolgaya's method }\end{array}$} & \multicolumn{4}{|c|}{$\begin{array}{l}\text { Parameters of generated impact by } \\
\text { Dmitrovskaya's method }\end{array}$} \\
\hline $\mathrm{P}_{\mathrm{Ia}}$ & $P_{\kappa}$ & $\mathrm{P}_{\mathrm{PGA}}$ & $\begin{array}{l}\mathrm{PGA}, \\
\left(\mathrm{m} / \mathrm{s}^{2}\right)\end{array}$ & $\begin{array}{l}\mathrm{I}_{\mathrm{A}} \\
\left(\mathrm{m}^{2} / \mathrm{s}^{3}\right)\end{array}$ & $\begin{array}{l}\mathrm{CAV}, \\
(\mathrm{m} / \mathrm{s})\end{array}$ & $\begin{array}{l}\text { displacement, } \\
(\mathrm{m})\end{array}$ & $\begin{array}{l}\mathrm{PGA}, \\
\left(\mathrm{m} / \mathrm{s}^{2}\right)\end{array}$ & $\begin{array}{l}\mathrm{I}_{\mathrm{A}} \\
\left(\mathrm{m}^{2} / \mathrm{s}^{3}\right)\end{array}$ & $\begin{array}{l}\mathrm{CAV}, \\
(\mathrm{m} / \mathrm{s})\end{array}$ & $\begin{array}{l}\text { displacement, } \\
(\mathrm{m})\end{array}$ \\
\hline 0 & 0.3 & 0.7 & 7.04 & 24.4 & 7.44 & 0.095 & 7.49 & 51.55 & 16.3 & 0.071 \\
\hline 0.1 & 0.3 & 0.6 & 6.88 & 33.94 & 11.78 & 0.065 & 7.46 & 51.22 & 16.26 & 0.082 \\
\hline 0.2 & 0.3 & 0.5 & 7.07 & 32.88 & 9.84 & 0.123 & 7.24 & 48.77 & 15.85 & 0.064 \\
\hline 0.4 & 0.3 & 0.3 & 7.5 & 32.25 & 12.25 & 0.127 & 8.01 & 48.79 & 15.19 & 0.152 \\
\hline 0.5 & 0.3 & 0.2 & 7.57 & 32.58 & 9.44 & 0.14 & 7.07 & 45.7 & 15.38 & 0.060 \\
\hline 0.6 & 0.3 & 0.1 & 5.13 & 34 & 16.25 & 0.149 & 7.19 & 48.5 & 15.82 & 0.063 \\
\hline \multicolumn{3}{|c|}{ El Centro } & \multicolumn{2}{|l|}{7.63} & \multicolumn{2}{|l|}{37.27} & \multicolumn{2}{|l|}{17.98} & \multicolumn{2}{|l|}{0.135} \\
\hline \multicolumn{3}{|c|}{ Tabas } & \multicolumn{2}{|l|}{7.31} & \multicolumn{2}{|l|}{51.27} & \multicolumn{2}{|l|}{27.76} & \multicolumn{2}{|l|}{0.167} \\
\hline \multirow{2}{*}{\multicolumn{3}{|c|}{$\begin{array}{l}\text { Estimated } \\
\text { parameters }\end{array}$}} & \multicolumn{2}{|c|}{7} & \multicolumn{2}{|c|}{52.6} & \multicolumn{2}{|c|}{30} & \\
\hline & & & \multicolumn{2}{|c|}{ PGA, $\left(\mathrm{m} / \mathrm{s}^{2}\right)$} & \multicolumn{2}{|c|}{$\mathrm{I}_{\mathrm{a}},\left(\mathrm{m}^{2} / \mathrm{s}^{3}\right)$} & \multicolumn{2}{|c|}{$\mathrm{CAV},(\mathrm{m} / \mathrm{s})$} & \multicolumn{2}{|l|}{$\frac{\text { OTs. }}{\text { displa }}$} \\
\hline
\end{tabular}

Table 3. Comparison spectra of two models of the calculated input generation

\begin{tabular}{|c|c|c|}
\hline Function type & Dolgaya's model & Dmitrovskaya's model \\
\hline $\begin{array}{l}\text { Generated } \\
\text { accelerograms }\end{array}$ & 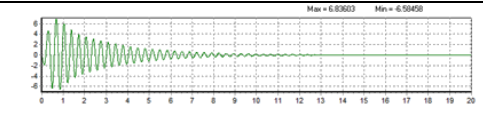 & $\sqrt[3]{\int_{0}}$ \\
\hline $\begin{array}{l}\text { Acceleration } \\
\text { spectra }\end{array}$ & 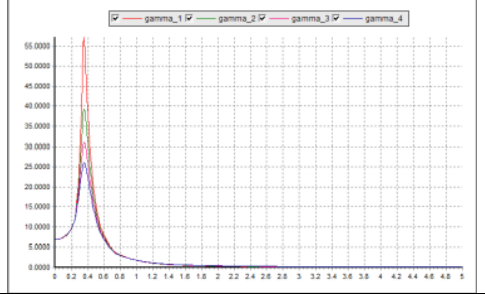 & 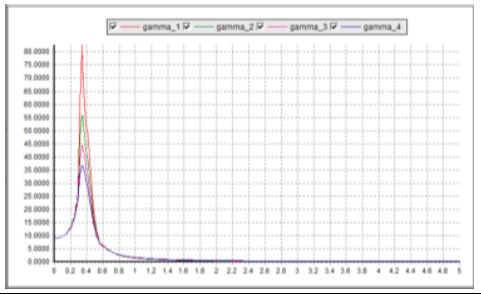 \\
\hline $\begin{array}{l}\text { Displacement } \\
\text { spectra }\end{array}$ & 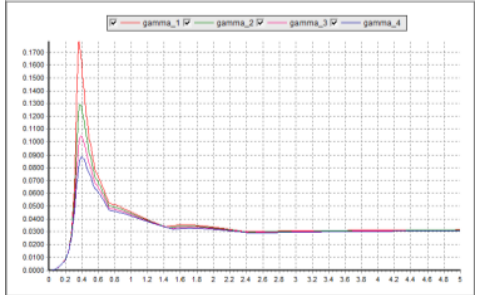 & 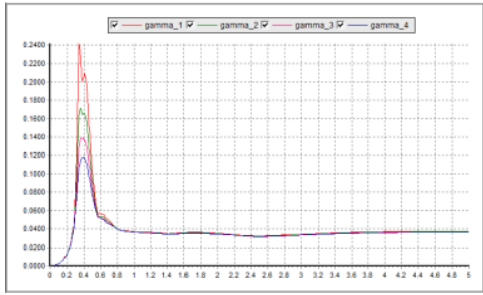 \\
\hline PFW spectra & $\mid$ & 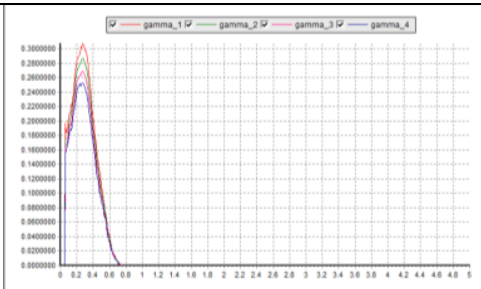 \\
\hline Damage spectra & 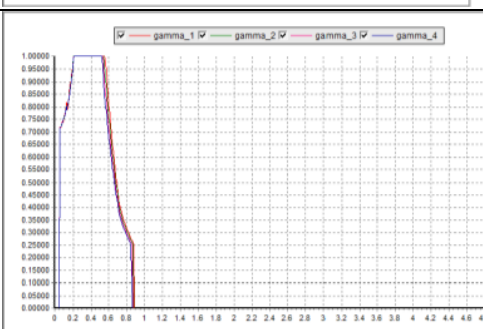 & 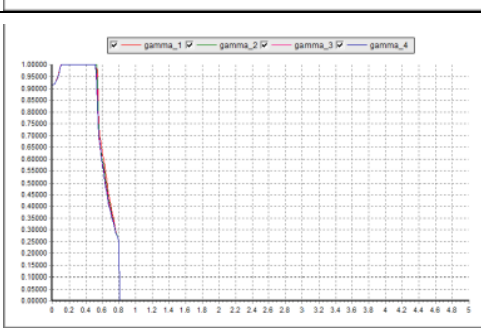 \\
\hline
\end{tabular}


Table 3 shows two models generated by the considered methods. Both models are built for the same values of the weight factors $\mathrm{P}_{\mathrm{IA}}=0.3, \mathrm{P}_{\mathrm{PGA}}=0.4, \mathrm{P}_{\kappa}=0.3$. The figure shows the generated accelerograms, their spectra of accelerations, displacements, work of the plastic deformation forces and damage. It is clearly seen that the new model is more conservative both in accelerations, and in displacements as well as in the energy of plastic deformations.

Note that both models are narrowband. This is due to the relatively small harmonic coefficient of both models. You can make the model more "chaotic" by increasing the value of $\kappa$ and its weight factor, but this solution violates the principle of the mode conservativeness.

\section{Conclusions}

The studies performed allow us to draw a number of conclusions important for the practice of earthquake engineering.

1) There are simple models of seismic actions, which, according to their kinematic, energy and spectral characteristics are quite suitable for structural analysis of seismic resistance.

2) When generating such processes, it is important to take into account both the properties of real actions and the limiting state of the calculated structure

3) The considered models of seismic inputs should be applied in the following cases:

- when designing mass construction projects, when it is not possibility to get a package of design accelerograms

- in case of typical designing, when the design object can be located on sites of different seismic and geological conditions

- at early stages of designing important objects, when the package of design accelerograms is not available yet, but to make technical solutions is necessary at the moment.

4) Seismologists should take part in input setting in to two cases

- when the cost of anti-seismic strengthening based on calculating using artificial accelerograms is excessively high, and it is hoped that the refining the initial action records can lead to significant cost savings

- when seismologists can reliably predict the absence of resonance actions for a construction on the construction site. For example, such situation can be found in Armenia, where a large number of seismically isolated buildings with the main tone period of 2-3 s are built, and seismologists state that no actions with periods higher than $0.5 \mathrm{~s}$ can occur in Armenia.

The authors are grateful to S.R. Grebenshchikova for her help in preparing the English version of the paper and Ph.D. A.A. Dolgaya for help in making the calculations. The work was carried out with the support of the grant of the Russian Foundation for Basic Research No 19-35-90111

\section{References}

1. Y. Wang, B. Chen et al., IFAC-PapersOnLine, 1-50, 3811-3816 (2017), doi:10.1016/j.ifacol.2017.08.486

2. J. Zhou, K. Tang et al., Journal of Earthquake Engineering, 18-5, 816-830, (2014) doi:10.1080/13632469.2014.908152

3. M. Yamamoto, Y. Sato, S. Inoue, Japan Architectural Review, 1-3, 322-330 (2018), doi:10.1002/2475-8876.12035 
4. R. A. McConnell, National Symposium on Electromagnetic Compatibility, (1989) doi:10.1109/nsemc.1989.37151

5. J. T. Kozák Earthquake Source Asymmetry, Structural Media and Rotation Effects, 310 (2006). doi:10.1007/3-540-31337-0_1

6. A. Kim, O. Lukovenkova et al., E3S Web of Conferences, 20, 02003, (2017) doi:10.1051/e3sconf/20172002003

7. O. Lukovenkova, Y. Marapulets et al., E3S Web of Conferences, 62, 02012, (2018) doi:10.1051/e3sconf/20186202012

8. O. A. Savinov, A. M. Uzdin et al., Soil Mechanics and Foundation Engineering, 32-4, 124-129 (1995), doi:10.1007/bf02336273

9. P. Léger, M. Leclerc, Engineering Structures, 18-3, 227-239 (1996). doi:10.1016/0141-0296(95)00146-8

10. , O. P. Nesterova, Bulletin of Civil Engineers, 2-16, 48-53 (2019). doi:10.23968/19995571-2019-16-2-48-53.

11. T.V. Ivanova, J. Guan et al., Magazine of Civil Engineering, 75-7, 129-138 (2017). doi: 10.18720/MCE.75.13.

12. G.A. Bogdanova, A.A. Dolgaya et al., 12th World Conference on Earthquake Engineering, New Zealand, 1358 (2000)

13. I. P. Pryadko, Vestnik MGSU, 11, 97-104 (2012). doi:10.22227/19970935.2012.11.97-104

14. A. Perelmuter, V. Slivker, Springer Science \& Business Media, (2013) doi:10.1007/978-3-540-36500-6_5

15. A. Yanik, U. Aldemir, M. Bakioglu Earthquake Resistant Engineering Structures 8, (2011) doi:10.2495/eres110061

16. K.K.F. Wong Journal of Earthquake Engineering, 8-2, 315-334 (2004). doi:10.1080/13632460409350491

17. K. W. Campbell, Y. Bozorgnia, Earthquake Spectra, 28-2, 457-485, (2012) doi:10.1193/1.4000012

18. B. A. Bradley, Soil Dynamics and Earthquake Engineering, 78, 89-98 (2015). doi:10.1016/j.soildyn.2015.07.009

19. T. Crespellani, C. Madiai, G. Vannucchi, Analysis and Design of Retaining Structures against Earthquakes (1996), doi:10.1061/9780784402061.008

20. G. L. Choy, J. L. Boatwright New Manual of Seismological Observatory Practice, 2, 19 (2012), doi:10.4095/222533

21. H.B. Ozmen, M. Inel, Earthquakes and Structures, 6-10, 1315-1330 (2016). doi:10.12989/eas.2016.10.6.1315

22. E. Faccioli, R. Paolicci, Ju. Rey, Earthquake Spectra, 2-20, 347-376 (2004). doi:10.1193/1.1707022

23. A.N. Birbrayer Raschet konstruktsiy na seysmostoykost, (Nauka, SPb, 1998) 